\title{
Dagoberto Gutiérrez: \\ "El trabajo universitario ha de recuperar el sentido crítico, ha de recuperar la humanidad para los seres humanos"
}

ENTREVISTA Por Evelyn MartíneZ

Realizamos una entrevista a Dagoberto Gutiérrez, vicerector de la Universidad Luterana Salvadoreña (ULS). Conversamos sobre la situación actual de la educación en el contexto mundial de crisis, y sobre los desafíos de las universidades ante los problemas actuales.

EM: En el contexto de la crisis capitalista mundial, parece que hay un derrumbe de las principales corrientes de pensamiento y paradigmas dominantes. En ese sentido, ¿cómo ve la situación de la educación en el contexto mundial actual?

DG: En la pregunta hay varios componentes claves que pueden determinar la respuesta. El primero engloba la figura del contexto, porque uno entiende que el contexto es una serie de variantes económicas, culturales, hasta psicológicas, económicas por supuesto, militares, que determinan un momento específico y establecen una determinada manera de ver y entender el mundo. El contexto se va configurando; por determinados momentos, el contexto tiene una permanencia, determinada permanencia, mientras en su seno se producen las fuerzas que determinaran el cambio de ese contexto.

Justamente hoy hay una serie de procesos que determinan un cambio de contexto, y ocurre que cuando hay un cambio de contexto también se construyen las condi- 
ciones para un cambio de texto, es decir, la forma de entender el mundo, la forma de leer el mundo, y la forma de construir el mundo y de transformar el mundo. Hay un cambio de contexto que también produce un cambio de texto.

Es por eso un momento crucial, es decir un momento en donde aparecen, como en cruz, más de un camino. Si cambia el contexto que determinaba un pensamiento principal, dominante y predominante, este pensamiento determinaba un camino, y probablemente un sólo camino. A ese camino único en donde predomina el reino del mercado a contrapelo del interés del Estado y del interés de la naturaleza y de los seres humanos, a ese único camino, que era el predominante, los poderes dominantes le llamaban de diferentes maneras.

Hoy aparece un momento crucial en donde a ese camino se enfrentan otros caminos, se contraponen otros caminos. $Y$ aquí hay una manera diferente de entender el mundo, y una manera diferente de sentir el mundo.

¿Qué tiene esto que ver con el trabajo de las universidades? El trabajo de las universidades, si se relaciona con la ciencia, con la producción de pensamiento, con una determinada manera de leer el mundo en esta coyuntura, está presionada a incorporar en su trabajo y en su producción intelectual los nuevos ecos que la nueva coyuntura está proporcionando, aquí es donde aparece la figura del desafío para las universidades. La coyuntura en sí, el quiebre de un contexto en sí, es un reto, es decir, es un dato de la realidad, pero en la manera en que la universidad asuma ese dato nace el desafío. Estamos diciendo que el reto es un hecho objetivo, el desafío tiene que ver con la forma como la universidad asuma el momento, y aquí aparece otro aspecto, la universidad ha de asumir el momento como una carga, pero ha de pasar a encargarse de esa carga, esto quiere decir que la universidad ha de asumir, como parte de su trabajo, el conocimiento de la cambiante realidad actual; dos, la interpretación de esa realidad; tres, su aporte a la transformación de esa realidad justamente situada en la cruz-calle que la coyuntura está proporcionándonos, de tal manera que la sociedad salvadoreña camine por un nuevo camino, por una nueva senda. Este es el desafío de la universidad, desde su trabajo.

EM: En la actualidad sigue perviviendo una lógica de educación bancaria, pasiva y acrítica ante la realidad nacional e internacional, entonces ¿Qué tipo de personas se deben formar en las universidades? ¿Cuáles son los desafíos de las universidades actualmente?

DG: Correcto. Esta segunda pregunta se inscribe justamente en los linderos de la anterior respuesta. 
La universidad ha de asumir, ante la realidad, una actitud negativa. Normalmente se entiende, y así se difunde, y así se enseña, que el ser humano ha de ser positivo ante la realidad y se dice que hay que ser positivo; pero en realidad, ante la realidad del ser humano ha de ser negativo y esto quiere decir que ha de conservar, defender, y promover una actitud crítica, esto como ser humano. Ahora bien, como universidad ha de desarrollar una política crítica, ya no se trata de una actitud, la actitud está referida a la persona, pero para el caso de la universidad se trata de una política crítica ante la realidad, en donde se inscriba en esa política crítica todo su trabajo, de tal manera que el ser humano, formado en la universidad, no ha de ser formado simplemente como profesional, como dueño de una profesión, sino ha de ser formado como ser humano. Esto aunque parece una cosa elemental, no lo es, porque ocurre que esto resulta ser la raíz crítica del trabajo de la universidad, porque en el contexto del reinado del mercado, el ser humano pierde humanidad, y deja de ser contextuado como ser humano, para ser construido como consumidor.

Cuando la universidad hace un trabajo en el sentido del desarrollo de la actitud crítica trata de recuperar la humanidad para el ser humano, y aquí hay una confrontación total con el mercado. $Y$ esto quiere decir que el trabajo universitario ha de reconocer, que en este momento, el enemigo principal de la humanidad y de la humanización de la humanidad es el mercado capitalista. Ese mercado al convertir todas las cosas en mercancías, al ponerle precios a todas las cosas, y al determinar que todo se compra y todo se vende, está eliminando a la humanidad.

El trabajo universitario ha de recuperar el sentido crítico, ha de recuperar la humanidad para los seres humanos, y ha de establecer una armonía entre pensar la realidad y sentir la realidad. Esta es la base del trabajo científico universitario.

EM: La ULS se concibe como una universidad comunitaria, sin fronteras y preocupada por los problemas ecológicos, ¿Qué hace actualmente la ULS ante los problemas de las comunidades? ¿Cuál debería ser el modelo de universidad que se propone construir en nuestro país?

DG: Correcto, hay tres componentes que bien definen a la Universidad Luterana: sin fronteras, comunitaria y preocupada por la temática ecológica, esto la define bastante bien. $\mathrm{Y}$ en el momento actual que vive El Salvador, éstas características delinean una universidad complicada con la realidad de la sociedad en la que está situada, una universidad en choque con esa realidad, en conflicto con esa realidad. Hasta cierto punto, éstas 
características de la ULS la sitúan en el terreno del desorden, es decir, una universidad enfrentada a un orden actual, proponiendo un orden diferente, que no es, pero que será, y trabajando en el terreno del orden y también en el terreno del desorden.

Esto quiere decir que en el momento actual una universidad para considerarse universidad, es decir, con un accionar y un pensamiento universal, lo menos que tiene que hacer es no aceptar el papel de rodaje del sistema, y trabajar de tal manera de conflictuarse con el orden actual. Si una universidad actúa armoniosamente, en concordancia, durmiendo en la misma cama del orden actual, puede ser una empresa exitosa, una empresa eficiente, pero no universidad.

Ocurre lo mismo que ocurre con las iglesias, cuando una iglesia es la niña bonita del orden dominante, esa iglesia puede estar siendo prostituida. Cuando una iglesia es perseguida y sus obispos son asesinados, esa iglesia es la iglesia del pueblo.

EM: El conocimiento no sólo se crea y recrea en la academia, en la universidad, sino que se enriquece desde el pueblo, ¿De qué manera la universidad debe convertirse en insumo de los movimientos sociales? ¿Y cuál debiera ser el aporte de ésta en la construcción de una sociedad alternativa?
DG: Hay una buena figura ahí, porque ciertamente el conocimiento no sólo es producto de la academia. Si uno entiende que la inteligencia de este animal humano parte de la capacidad de establecer y de construir los puentes con la realidad, esa es la inteligencia, entendamos así la inteligencia, y entendamos así el trabajo de la investigación. Normalmente uno piensa que hay investigación donde hay laboratorios, donde hay probetas, donde hay químicos, olvidando que científicos de la estatura de Einstein, por ejemplo, eran físicos teóricos, y aunque no estaban totalmente alejados de laboratorios, no era el laboratorio su hogar, sino la inteligencia estaba basada en la forma como este ser humano se relacionaba con su realidad, la realidad cercana, y la realidad lejana, y la realidad universal.

Aquí se trata de eso, si la Universidad Luterana es una universidad comunitaria, la producción de pensamiento necesita ser para la universidad todo un trabajo que parta de las mismas comunidades, tomando en cuenta el conocimiento ancestral, el conocimiento tradicional, hasta el conocimiento científico, esta manera de elaborar conocimiento es hoy por hoy una necesidad para nuestro país.

El Salvador atraviesa por un proceso de evidenciamiento de sus deficiencias geopolíticas, y necesita aprender a sobrevivir en este mun- 
do en donde se destruyan lógicas económicas tradicionales, lógicas de mercado tradicionales. ¿Cómo sobrevive el país?, y ¿cuál es el aporte de las universidades a eso? Las universidades han de ser capaces de construir los puentes que nos lleven a alcanzar el conocimiento ancestral de nuestras comunidades tradicionales, porque ahí encontraremos respuestas a los problemas acuciosos de hoy.

Y esto significa aprender a leer la realidad como presupuesto para aprender a leer los libros, y aprender a leer los libros como presupuesto para aprender a leer la realidad. En una primera mirada uno piensa que se trata de llevar la comunidad a la universidad, pero en una segunda mirada uno descubre que se trata de llevar la universidad a la comunidad, y ambas, comunidad y universidad, construir construyendo la sensibilidad necesaria, humana y social para producir el conocimiento que necesitamos hoy. Este conocimiento de nuestra realidad, de nuestras debilidades, de nuestras fuerzas, de nuestros recursos, resulta fundamental para sobrevivir como país y también como universidad. 